\title{
Influence of Diamond Sono-Abrasion, Air-Abrasion and Er:YAG Laser Irradiation on Bonding ofDifferentAdhesive Systems to Dentin
}

Marcelo Tavares de Oliveira, DDS,MS

Patrícia Moreira de Freitas ${ }^{b}, \mathrm{DDS}, \mathrm{MS}, \mathrm{PhD}$

Carlos de Paula Eduardoc,DDS,MS,PhD

Glaucia Maria Bovi Ambrosano ${ }^{\mathrm{d}}, \mathrm{PhD}$

Marcelo Gianninie,DDS,MS,PhD

\section{ABSTRACT}

Objectives: Different surface treatments may affect bonding performance of adhesive systems to dentin. This study evaluated the influence of different methods of surface treatment on adhesion of bonding agents to dentin.

Methods: Dentin surfaces abraded with \#600-grit SiC paper were used as control. Three methods of surface treatment (sono-abrasion, air-abrasion and Er:YAG laser irradiation) were used under specific parameters. Four adhesive systems (Tyrian, Clearfil SE Bond, Unifil Bond and Single Bond) were applied to treated surfaces, according to the manufacturers' instructions. Composite blocks were built on bonded surfaces, then restored teeth were vertically and serially sectioned to obtain bonded slices for interfacial micromorphologic analysis or to produce beam specimens for $\mu$-TBS bond test. Data were analyzed with two-way ANOVA and Tukey test at a significance level of $5 \%$.

Results: The results indicated that the preparation of dentin with sono-abrasion or laser did not affect the bond strength, while the preparation of dentin with SiC paper and air-abrasion influenced the bond strength for some systems. A clear difference of the preparation of dentin surfaces and formation of hybrid layer and resin tags were noted.

Conclusion: Bonding effectiveness of both the etch-and-rinse and the self-etch adhesives can be influenced by different methods of dentin preparation. (Eur J Dent 2007;1:158-166)

Key words: Dentin; Bond strength; Adhesive systems; Er:YAG laser; Sono-abrasion; Air-abrasion.

\section{INTRODUCTION}

In conventional restorative dental treatment,

a Doctoral student, Department of Restorative Dentistry, State University of Campinas, Piracicaba, SP, Brazil.

b Assistant Professor, Department of Restorative Dentistry, University of São Paulo, São Paulo, SP, Brazil.

Professor, Department of Restorative Dentistry, University of São Paulo, São Paulo, SP, Brazil.

d Associate Professor, Department of Social Dentistry/ Biostatistics, State University of Campinas, Piracicaba, SP, Brazil.

e Associate Professor, Department of Restorative Dentistry, State University of Campinas, Piracicaba, SP, Brazil.

rotary instruments are routinely used to remove caries lesions and to prepare the cavities. ${ }^{1,2} \mathrm{How}$ ever, it is common for patients to be fearful and anxious about receiving dental care, particularly with conventional treatment. ${ }^{3,4}$ Alternative methods of caries removal and cavity preparation have

- Corresponding Author: Prof. Dr. Marcelo Giannini Department of Restorative Dentistry Piracicaba School of Dentistry, State University of Campinas Av. Limeira, 901, Piracicaba, SP, 13414-900, Brazil Phone: 55-19-34125338 Fax: 55-19-21065218 e-mail: gianninidfop.unicamp.br 
been suggested to overcome the fear and the anxiety, and to eliminate the patient discomfort caused by air turbine and drilling noises. 5

Diamond sono-abrasion, air-abrasion and Erbium:YAG (Er:YAG) laser irradiation technologies have been introduced as alternatives to conventional mechanical rotary instruments. ${ }^{5-10}$ Diamond sono-abrasion is a system with preparation tips mounted on a sonic device that oscillates in a very short length avoiding over preparation and causing no damage to adjacent tooth during cavity preparation. Air-abrasion with aluminum oxide basically consists of the application of an abrasive jet with particles of different diameters and may be indicated for the removal of caries and restorative materials treating the surface possibly increasing adhesion of composite to dentin. Finally, the Er:YAG laser has been advocated to prepare microcavities due to its wavelength that closely approximates the absorption peak of water, so high ablation rates can be obtained at tooth substrates. To protect pulp tissue and to prevent melting of tooth tissue, laser irradiation should always be accompanied by water cooling to prevent cracking of dental substrates.

In addition to these new technologies for operative dentistry procedures, several researches have been developed in order to evaluate interactions between mineralized dental tissues and biomaterials. ${ }^{11,12}$ Self-etching dentin bonding agents have been indicated to bond composite restorative materials to dental tissues. 1,9,10 Studies have shown that self-etching systems have advantages in clinical application and restoration durability in comparison with conventional etch-and-rinse adhesive systems. ${ }^{11,12}$

Etch-and-rinse adhesive systems are applied to dentin after etching (30-40\% phosphoric acid gell and moisture control, while self-etching systems are applied directly to prepared dentin without etching, rinsing and moisture control steps. Etching with phosphoric acid removes the smear layer and demineralizes the dentin up to a depth of $3-7 \mu \mathrm{m}^{13}$; this procedure might overcome the influence of the smear layer as well as of the prepared dentin surface on composite bonding. ${ }^{14-}$ ${ }^{16}$ Conversely, studies have reported that the type of smear layer formed by the instrument or excavation method, and the hybridization process or interaction that take place when resin adhesive infiltrates into dentin, affect the quality of bonding between the prepared dentin surface and the selfetching adhesive system. ${ }^{15-17}$

While the alternative cavity preparation technologies are undoubtedly efficient, concerns have been expressed regarding the use of self-etching systems applied to dentin treated with different tooth preparation methods. ${ }^{16,17}$

This research examined the effect of air-abrasion, diamond sono-abrasion, Er:YAG laser irradiation and 600 -grit silicon carbide sandpaper abrasion (SiC-paper) on bonding to dentin treated with self-etch primer systems and etch-and-rinse adhesive. The $\mu$-TBS bond strength and micromorphological characteristics of prepared surfaces and resin-dentin interfaces were evaluated. The null hypothesis is that different surface treatments promote similar bond strength to dentin regardless of the adhesive system.

\section{MATERIALS AND METHODS}

\section{Specimen Preparation and}

\section{Experimental Groups}

Extracted, caries-free human third molars were used in this study, in accordance with the protocols approved by the institutional review board of the Piracicaba School of Dentistry - University of Campinas (150/2002). Ninety-six teeth were transversally sectioned with a diamond disc (Isomet, Buehler Ltd., Lake Bluff, IL, USA) under water cooling to remove occlusal enamel and expose flat, mid-coronal dentin surfaces. Teeth were randomly assigned to sixteen experimental groups ( $n=6)$, according to the type of dentin treatment (\#600-grit SiC-paper abrasion; air-abrasion, diamond sono-abrasion, Er:YAG laser irradiation) and the adhesive system applied (Tyrian SPE/OneStep Plus; Clearfil SE Bond; Unifil Bond; Single Bond) (Table 1).

\section{Dentin Treatment Protocols}

The methods used for dentin surface preparation were in accordance with the following protocols:

600-grit SiC-paper abrasion: The dentin surface was abraded with a \#600-grit SiC paper (3M do Brasil, Sumaré, SP, Brazil), on a polishing machine (APL-4, Arotec S.A. Ind. Com., Cotia, SP, Brazil) under water cooling for 15 seconds. This treatment was used as control. 
- Air-abrasion: The dentin surface was sandblasted with a stream of $27 \mu \mathrm{m}$ aluminum oxide particles at 50 psi pressure for $20 \mathrm{~s}$ (Air Touch Cavity Detection and Treatment System, Midwest Dental - Dentsply, Des Plaines, IL, USA). The internal nozzle tip diameter was $0.46 \mathrm{~mm}$ and was kept at a distance of approximately $2 \mathrm{~mm}$ from the dentin. Airborne particle abrasion was done in two different directions (mesio-distal and buccal-lingual) with the nozzle held at $45^{\circ}$ to the surface.

- Diamond sono-abrasion: An air-scaler (Profi II Ceramic, Dabi Atlante, Ribeirão Preto, SP, Brazil) oscillating at $28 \mathrm{KHz}$ sonic frequency was the power transmitter used to activate the CVD-US diamond-coated tip (Clorovale Diamantes, São José dos Campos, SP, Brazil). The dentin surface was treated with a cylindrical diamond tip $110 \mathrm{~mm}$ long $X 1.4 \mathrm{~mm}$ diameter) under $70 \mathrm{psi}$ air pressure and $30 \mathrm{~mL} / \mathrm{min}$ of water spray cooling for $60 \mathrm{~s}$. Sonoabrasion was applied in two different directions (mesio-distal and buccal-lingual).

- Er:YAG laser irradiation: Dentin was irradiated with a pulsed Er:YAG laser (Key Laser 3, Kavo, Biberach, Germanyl at a wavelength of $2.94 \mu \mathrm{m}$, a pulse duration of 250-500 $\mu$ sec under water cooling ( $5 \mathrm{~mL} / \mathrm{min}$ ). The output power and repetition rate of this equipment was $200 \mathrm{~mJ}$ and $4 \mathrm{~Hz}$, re- spectively. The beam diameter at the focal area for the handpiece \#2065 was $0.63 \mathrm{~mm}$ and the handpiece was held perpendicular to the dentin surface at a distance of $12 \mathrm{~mm}$ (focused mode). Samples were irradiated by hand, scanning the surface once in each direction, horizontally and vertically, to ensure homogeneous irradiation on the entire surface area. The irradiation was performed with a water cooled spray $(5.0 \mathrm{~mL} / \mathrm{min})$. The energy density used for the laser irradiation was $64.2 \mathrm{~J} / \mathrm{cm}^{2}$.

\section{Micro-tensile bond strength}

Sixty-four teeth were used to perform the $\mu$-TBS bond test. Sixteen teeth were randomly selected from each dentin treatment and bonding systems were applied to the prepared dentin according to the manufacturers' instructions. Afterwards, they were light-cured for 10 seconds (XL 3000, 3M Espe, St. Paul, MN, USA). Resin composite buildups were incrementally constructed on the polymerized bonding agent in five layers (1 $\mathrm{mm}$ thick) using a micro-hybrid composite (Clearfil APX, Kuraray Medical Inc). Each layer was then lightcured for 40 seconds using the same light-curing unit as mentioned previously. Restored teeth were stored in distilled water at $37^{\circ} \mathrm{C}$ for $24 \mathrm{~h}$. To obtain

Table 1. Compositions of adhesive systems used in this study.

\begin{tabular}{|c|c|c|}
\hline Adhesive Systems & Composition & Manufacturer \\
\hline $\begin{array}{l}\text { Tyrian SPE / One-Step Plus } \\
\text { (self primer) }\end{array}$ & $\begin{array}{l}\text { Primer: 2-Acrylamido-2-methyl propanesulfonic acid, } \\
\text { Bis (2-(methacryloyloxy) ethyl) phosphate, ethanol } \\
\text { (pH = 0.5). Adhesive: Biphenyl dimethacrylate, } \\
\text { hydroxyethyl methacrylate, acetone, glass frit. }\end{array}$ & $\begin{array}{c}\text { Bisco Inc., } \\
\text { Schuamburg, IL, USA }\end{array}$ \\
\hline $\begin{array}{l}\text { Clearfil SE Bond } \\
\text { (self-primer) }\end{array}$ & $\begin{array}{l}\text { Primer: Water, ethanol, MDP, HEMA, dimethacrylate } \\
\text { hydrophilic, camphorquinone, N, N-diethanol p- tolu- } \\
\text { idine ( } \mathrm{pH}=2.0 \text { ). Adhesive resin: MDP, Bis-GMA, HEMA, } \\
\text { dimethacrylate hydrophobic, camphorquinone, N, N- di- } \\
\text { ethanol p- toluidine, silanated colloidal sílica. }\end{array}$ & $\begin{array}{l}\text { Kuraray Medical Inc., } \\
\text { Kurashiki, Okayama, } \\
\text { Japan }\end{array}$ \\
\hline $\begin{array}{l}\text { UniFil Bond } \\
\text { (self-primer) }\end{array}$ & $\begin{array}{c}\text { Primer: HEMA, 4-MET, ethanol, water }(\mathrm{pH}=2.2) \text {. } \\
\text { Adhesive resin : UDMA, HEMA, TEGDMA, silanated col- } \\
\text { loidal silica. }\end{array}$ & $\begin{array}{l}\text { GC Corp., } \\
\text { Itabashi-ku, Tokyo, } \\
\text { Japan }\end{array}$ \\
\hline $\begin{array}{l}\text { Single Bond } \\
\text { (etch \& rinse) }\end{array}$ & $\begin{array}{c}\text { Etchant: 35\% phosphoric acid. } \\
\text { Adhesive: Bis-GMA, HEMA, ethanol, water, UDMA, } \\
\text { Bisphenol A glycerolate, polyalkenoic acid copolymer, } \\
\text { dimethacrylate, camphorquinone }(\mathrm{pH}=4.3) \text {. }\end{array}$ & $\begin{array}{l}\text { 3M ESPE, } \\
\text { St. Paul, MN, USA }\end{array}$ \\
\hline
\end{tabular}


tooth fragments with bonded composite, the tooth was vertically sectioned serially in both " $x$ " and " $y$ " directions across the bonded interface, resulting in several bonded beams with a $0.8 \mathrm{~mm}^{2}$ crosssectional area.

Six beams were randomly selected from each restored tooth. Each bonded beam was fixed to $\mu$ TBS testing device with a cyanoacrylate adhesive (Zapit, DVA, Corona, CA, USA) and tested in tension at $0.5 \mathrm{~mm} / \mathrm{min}$ in a universal testing machine (4411, Instron Co., Canton, MA, USA) until they fractured. After fracture, the cross-sectional area of the debonded interface was measured to the nearest $0.01 \mathrm{~mm}$ with a digital caliper (727-6/150, Starret, Itu, SP, Brazil) and used to calculate test results in units of stress ( $\mathrm{MPa}$ ). Means of the six beams were calculated for each restored tooth fragment. Data were analyzed statistically by twoway ANOVA and the Tukey-Kramer post-hoc test. Statistical significance was established at 5\%.

\section{SEM Evaluations}

The roots of thirty-two teeth were removed and the crown section was longitudinally cut lbuccal-linguallyl into two-halves. Sixty-four tooth fragments were obtained. In order to evaluate the treated dentinal surface morphology under scanning electron microscopy (SEM) (VP 435, Leo, Cambridge, England), sixteen fragments were randomly selected $(n=4)$. Dentin surfaces were treated with four dentin treatment protocols (\#600-grit SiC paper, air-abrasion, sono-abrasion, laser irradiation). Fragments were dehydrated in ascending acetone concentrations $130 \%, 50 \%, 70 \%, 90 \%$ and 100\%), critical-point dried (CPD 030, Balzers, Balzer, Leichtenstein), sputter-gold coated (MED 010, Balzers, Balzer, Leichtenstein) and examined under SEM. Representative areas of the treated dentin surface were photographed at 5,000X.
For the SEM evaluation of the interfacial micromorphology, forty-eight dental fragments were used. The dentin surfaces were treated according to the described protocols and the adhesive systems were applied in accordance with the manufacturers' instructions ( $n=3)$. All restored teeth were vertically, serially sectioned into $2.0 \mathrm{~mm}$ thick slabs. The slabs were hand-polished with 600-, 1200-, and 2000-grit SiC paper followed by diamond pastes $(6 \mu \mathrm{m}, 3 \mu \mathrm{m}, 1 \mu \mathrm{m}$ and $0.25 \mu \mathrm{m})$. Slabs were rinsed and were ultrasonically cleaned during 12 minutes after each polishing step. After polishing, slabs were etched with $50 \%$ phosphoric acid for $15 \mathrm{~s}$, washed, and treated with $1 \%$ with $\mathrm{NaOCl}$ for $10 \mathrm{~min}$. Slabs were dehydrated in ascending acetone concentrations, critical-point dried, sputter-coated with gold and examined under SEM. Representative areas of the resin-dentin interfaces were photographed at 5,000X.

Fractured specimens were ultrasonically cleaned, allowed to air-dry overnight, sputter coated, and observed under SEM to determine the fracture modes.

\section{RESULTS}

Two-way ANOVA indicated significant differences for the type of dentin treatments $(P<.00001)$ and adhesive systems $(P<.00001)$. There was also interaction between factors ( $P<.00003)$. The mean $\mu$-TBS bond strength and standard deviation values are shown in Table 2. Tukey-Kramer post-hoc test showed that laser-treated or sono-abraded dentin did not affect the bond strength of adhesive systems. When the dentin was sandblasted with aluminum oxide particles Tyrian SPE/One-Step Plus presented significantly lower bond strength than Clearfil SE Bond, which were similar to Unifil Bond and Single Bond. For the dentin prepared with SiC paper, the bond strength of Clearfil SE

Table 2. Results of tensile bond strengths for experimental groups in MPa.

\begin{tabular}{|c|c|c|c|c|}
\hline \multirow{2}{*}{ Adhesive Systems } & \multicolumn{4}{|c|}{ Methods of tooth preparation } \\
\hline & $\mathrm{SiC} 600$ & Air-abrasion & Sono-abrasion & Er:YAG laser \\
\hline Tyrian SPE/One-Step Plus & $29.9(4.5) \mathrm{Ba}$ & 21.2 (2.7) Bab & $20.4(3.8) \mathrm{Ab}$ & $14.2(4.1) \mathrm{Ab}$ \\
\hline Clearfil SE Bond & 41.5 (2.9) Aa & $33.0(5.0) \mathrm{Aa}$ & $23.0(1.0) \mathrm{Ab}$ & $12.6(5.0) \mathrm{Ac}$ \\
\hline Unifil Bond & $20.4(6.4) \mathrm{Cb}$ & $30.1(8.6) \mathrm{ABa}$ & $20.5(4.6) \mathrm{Ab}$ & $11.8(4.5) \mathrm{Ab}$ \\
\hline Single Bond & $33.9(4.7) \mathrm{ABa}$ & 28.5 (1.3) ABab & $24.7(6.7) \mathrm{Ab}$ & $12.4(3.6) \mathrm{Ac}$ \\
\hline
\end{tabular}

Groups having different letters (upper case=column; lower case=row) are significantly different. 
Bond was higher than Tyrian and Unifil Bond, but similar to Single Bond. The dentin irradiation with Er:YAG laser at $64.2 \mathrm{~J} / \mathrm{cm}^{2}$ resulted in a reduction in bond strength values of all adhesive systems tested, but only Clearfil SE Bond and Single Bond was significantly decreased.

Figure 1A shows scratches left by the SiC abrasive paper and a regular smear layer over the entire surface, occluding the dentinal tubules. The air abrasion resulted in an irregular dentin surface without any patent tubules (Figure 1B). SEM examination of sono-abraded surfaces showed an amorphous layer of debris with completely obliterated dentin tubules (Figure 1C). Laser-treated dentin micromorphology showed lack of smear layer and a very rough, irregular surface. The peritubular dentin is evident around the tubules (Figure 1D).

Resin-dentin interdiffusion zone and resin tags were noted in all bonded interfaces on which both self-etching and etch \& rinse adhesive systems were used (Figures 2A, 2B, 2C, 2D and 2E). The thickness of hybrid layer and the length of resin tags varied according to the dentin treatment and the type of adhesive system applied. SEM of bonded specimens that were treated with the Er:YAG laser showed collar-like structures around resin tags for all bonded interfaces (Figures 2D and 2E).

Table 3. Failure mode (\%) of tested specimens.

\begin{tabular}{|c|c|c|c|c|c|c|c|c|c|c|c|c|c|c|c|c|}
\hline \multirow{3}{*}{$\begin{array}{l}\text { Failure } \\
\text { Type }\end{array}$} & \multicolumn{16}{|c|}{ Dentin Surface Treatments } \\
\hline & \multicolumn{4}{|c|}{ Diamond Sono-Abrasion } & \multicolumn{4}{|c|}{ Air-Abrasion } & \multicolumn{4}{|c|}{ Er:YAG Laser } & \multicolumn{4}{|c|}{ \#600-grit SiC Paper } \\
\hline & SB & SE & TY & UN & SB & SE & TY & UN & SB & SE & TY & UN & SB & SE & TY & UN \\
\hline Type 1 & 85 & 78 & 63 & 72 & 90 & 85 & 66 & 88 & 57 & 59 & 50 & 47 & 85 & 78 & 72 & 76 \\
\hline Type 2 & 5 & 8 & 15 & 6 & 5 & 5 & 9 & 0 & 9 & 13 & 10 & 21 & 0 & 15 & 18 & 7 \\
\hline Type 3 & 10 & 0 & 7 & 11 & 0 & 0 & 0 & 0 & 25 & 18 & 25 & 32 & 5 & 7 & 0 & 0 \\
\hline Type 4 & 0 & 14 & 15 & 11 & 5 & 10 & 25 & 12 & 9 & 10 & 15 & 0 & 10 & 0 & 10 & 17 \\
\hline
\end{tabular}
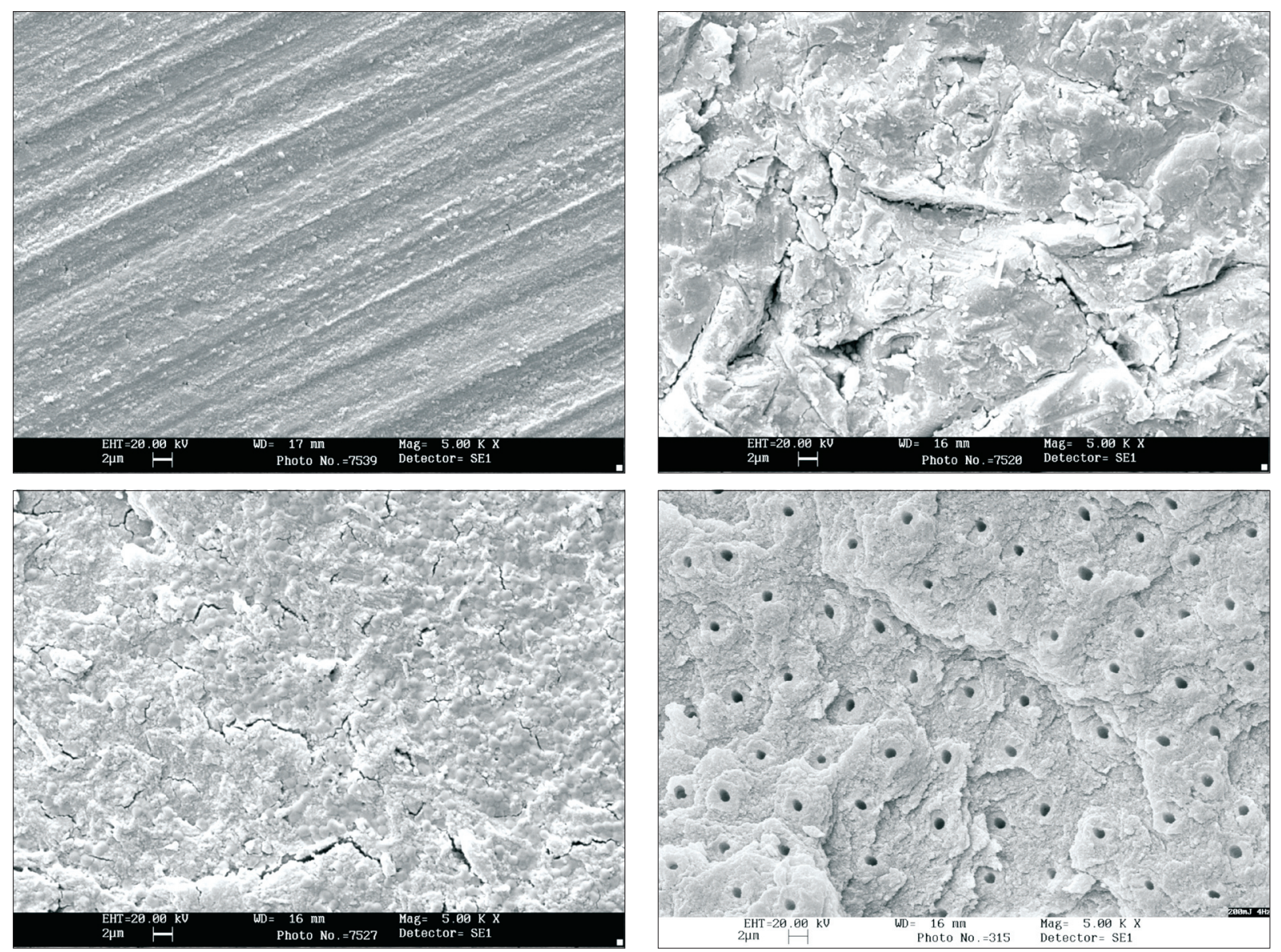

Figure 1. SEM of the prepared dentin surfaces (1A: 600-grit SiC-paper; 1B: air-abrasion with aluminum oxide particles; 1C: diamond sono-abrasion and 1D: laser Er:YAG irradiation) Original magnification 5000X. 
Table 3 shows the failure pattern observed in this study. The most predominant failure patterns on experimental groups were partial cohesive failure within adhesive layer and fracture between adhesive resin and dentin (47\% - 90\%) (Figure 3A). Laser-treated dentin tended to fail more cohesively in dentin after testing (Figure 3B).

\section{DISCUSSION}

The null hypothesis for this study had to be re-
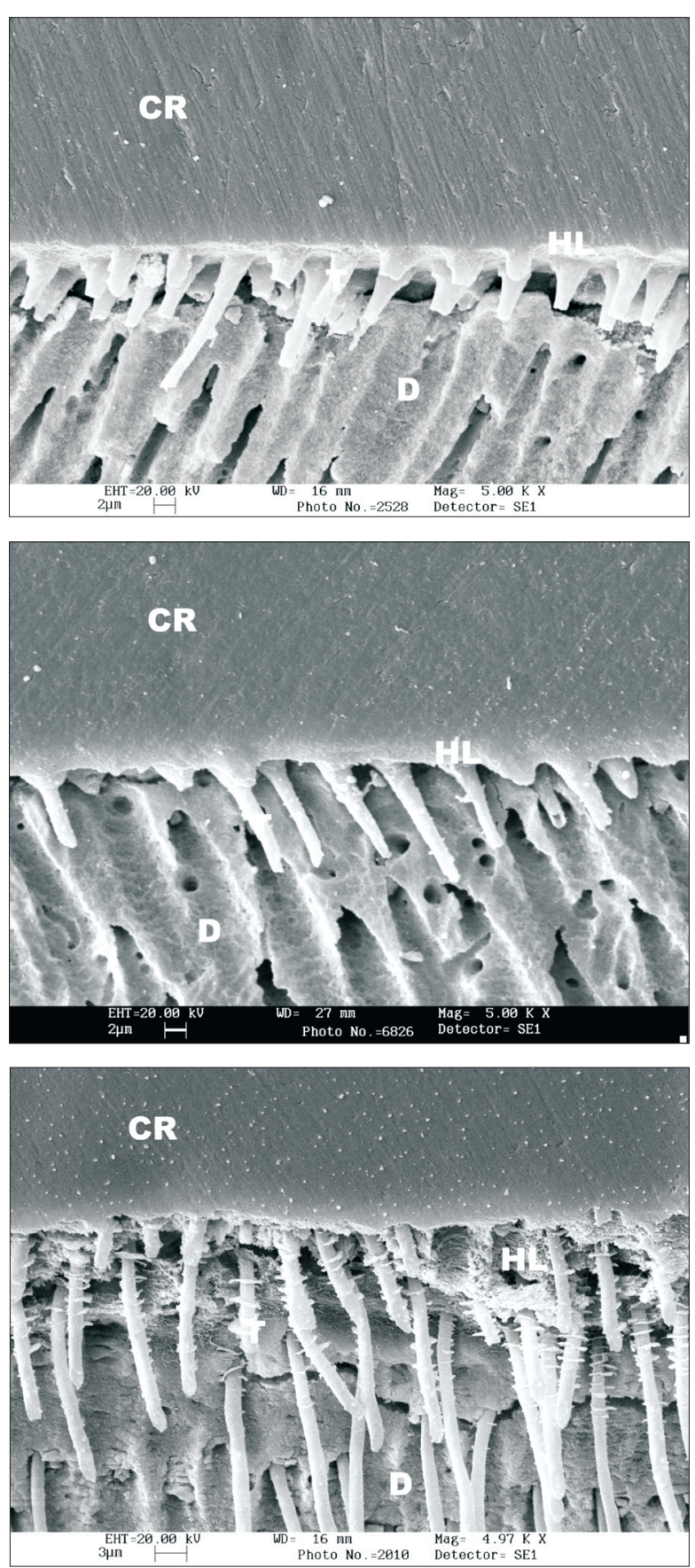

jected. In this study, in order to verify the effects of Er:YAG laser irradiation, air- and sono-abrasion preparation methods on bonding of composite resin to dentin, four adhesive systems were selected. Although the smear layer removal and the superficial demineralization promoted by the acid etching, the conventional, etch-and-rinse adhesive Single Bond was affected by the type of dentin preparation. This could have happened due to superficial changes promoted by surface treatments, modifying the way this adhesive system interacts with treated dentin. Higher bond strength values were observed when Single Bond was applied to $\mathrm{SiC}$-abraded dentin than when it was applied to diamond sono- and laser-treated dentin. Air-abrasion treatment resulted in similar bond strength to \#600-SiC paper and sono-abrasion treatments, but higher than laser irradiation. The acid etching changes the superficial dentin overcoming the effects of some preparation methods. ${ }^{17}$

The most important advantage of self-etching systems is that infiltration of adhesive resin
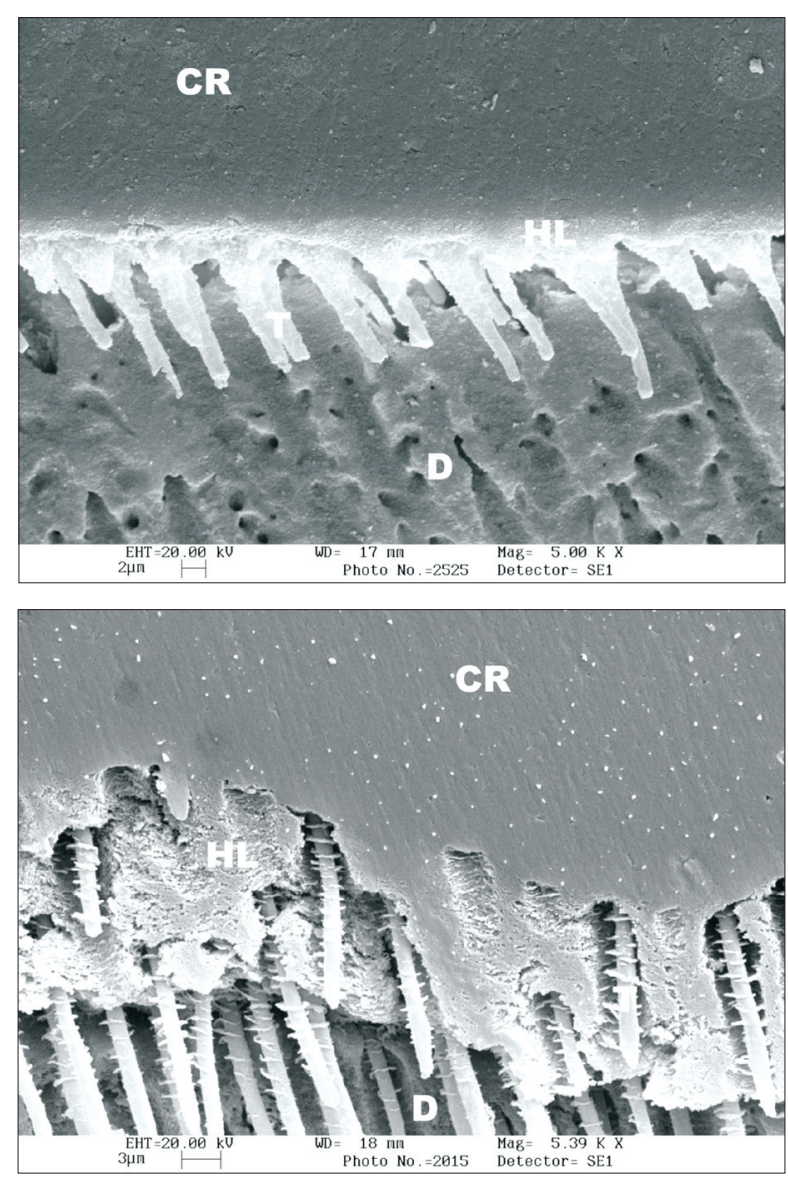

Figure 2. SEM of the bonded interfaces. Resin-dentin interface of Tyrian SPE/One-Step Plus bonded to dentin treated with SiC paper (2A). Resin-dentin interface of Clearfil SE Bond applied to air-abraded dentin (2B). Resin-dentin interface of Single Bond applied to sono-abraded dentin (2C). Resin-dentin interfaces of Tyrian and Unifil Bond applied to laser-treated dentin (2D and 2E)(CR- composite resin; HL- hybrid layer; D- dentin) Original magnification 5000X. 
occurs simultaneously with the self-etching process. ${ }^{18}$ This approach eliminates the rinsing and drying steps before applying the bonding agent. ${ }^{12,16}$ Depending on their etching aggressiveness or acid dissociation constants (pKa values), self-etching adhesive systems can be classified into strong, moderate and mild. The $\mathrm{pH}$ of Clearfil SE Bond and Unifil Bond adhesives are 2.0 and 2.2, respectively, and they are close to ideal acidity and etching aggressiveness. Conversely, the self priming etchant of Tyrian is considered as a strong self-etch primer with a very low pH (0.5), which can produce similar demineralization effects like phosphoric acid (30 to $40 \%$ ) on dentin and enamel. ${ }^{18}$ All self-etching systems tested were also influenced by dentin treatment.

The adhesive systems applied to laser-treated dentin presented similar bond strength values. However, when compared to the other dentin preparation methods they presented lower bond strength values. Erbium:YAG lasers emit a wavelength of $2904 \mathrm{~nm}$ that coincides with the main absorption peak of water. This emitted energy is also absorbed by hydroxyapatite. 19,20 The application of Er:YAG laser causes vaporization of the water, leading to volumetric expansion and ablation of dental hard tissues. The process of ablation is a consequence of a thermo-mechanical interaction
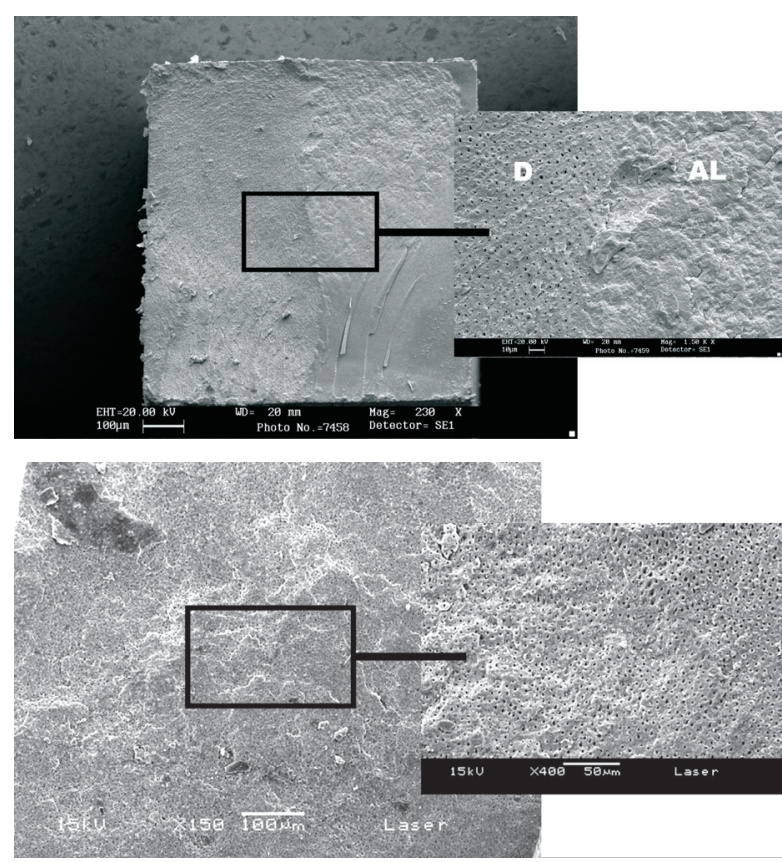

Figure 3. SEM photomicrographs illustrating fractured surfaces. Fractured dentin-adhesive (Unifil Bond) interface in dentin side (3A) (D- dentin; AL- adhesive layer). Cohesive fracture in dentin for Single Bond adhesive applied after laser irradiation (3B) Original magnification 230X - 1500X. between laser irradiation and dental mineralized tissues and produces a very irregular surface, free of smear layer and with a more prominent peritubular dentin than intertubular dentin (Figure 1D). 9,10,21-24

Studies have shown that Er:YAG irradiation of dentin can denaturize organic components within the intertubular dentin subsurface, which does not seem to be favorable for adhesion. ${ }^{25,26}$ The lasermodified layer can impair the mineral dissolution by acid etching and the resin adhesive diffusion into intertubular dentin subsurface, leading to a deficient hybridization and, consequently, to a lower bond strength. ${ }^{23,24,27,28}$ The laser-irradiated dentin samples tended to fail more cohesively in dentin (Figure 3B). The subsurface damaged can exceed the thickness of hybridization, leaving a weakened substrate, which could explain the cohesive fractures in dentin. ${ }^{16,23}$ The bond strength results for laser-irradiated dentin were the lowest values for Single Bond and Clearfil SE Bond adhesive systems. However, for Unifil Bond and Tyrian systems the bond strength was similar to others means of dental preparations.

Air abrasion offers an alternative to conventional dental handpieces because minimizes the heat, pressure, noise and vibration. The abrasion with $27 \mu \mathrm{m}$ aluminum oxide particles created an irregular surface morphology and the tubule openings were occluded by surface debris (Figure 1B). ${ }^{29-31}$ The surfaces were markedly changed for air abrasion and the increase of surface irregularity did not necessarily improve bond strength..$^{29,32}$ The performance of tested adhesive systems in air-abraded dentin was adequate and the bond strength ranged from 21.2 (Tyrian) to $33.0 \mathrm{MPa}$ (Clearfil SE Bond). For Unifil Bond, the application on air-abraded dentin resulted in the highest bond strength value when compared to other dentin treatments.

Diamond sono-abrasion is recommended for minimal cavity preparation of occlusal and proximal lesion. ${ }^{5,7}$ The sono-abrasion surface treatment resulted in dentin surfaces that were equally receptive to bonding agents. Bond strength ranged from 20.4 (Tyrian) to 24.7 MPa (Single Bond) and no significant difference was obtained on bond strength to air-abraded dentin, for self-etching and etch-and-rinse system.

The 600-grit control surfaces showed a typical 
smear layer with abrasion tracks from the grinding procedure (Fig. 1A). 1,15,29 This treatment is commonly used for in vitro studies to standardize and prepare dental surfaces for bonding procedures. However, differences in smear layers prepared with bur cutting or abrasive paper have been reported to affect the bond strengths of adhesive systems to dentin. ${ }^{15,33}$ In the current study, Unifil Bond presented the lowest bond strength values, while Single Bond and Clearfil SE Bond showed the highest, when the dentin was prepared with 600-grit SiC paper. These results can be explained by the quality of dentin hybridization and by monomeric composition of each material.

Within the limitations imposed by the $\mu$-TBS methodology, this study showed that the interaction between the adhesive systems and the resulting surfaces from dentin treatments might affect the quality of bonding between composite resin and dentin. Therefore, when preparing dentin, selecting the proper adhesive system is important for improvement of bonding. Further studies including, for example, TEM evaluation, might provide a more detailed analysis of the interaction between surface treatments and adhesive systems.

\section{CONCLUSIONS}

The treatment of dentin surfaces prior to bonding procedures affected the bond strength of all adhesives tested. Laser irradiated dentin showed lower bond strength than other dental preparation methods.

\section{REFERENCES}

1. Tao L, Pashley DH, Boyd L. Effect of different types of smear layer on dentin and enamel shear bond strengths. Dent Mater 1988;4:208-216.

2. Borges CFM, Magne P, Pfender E, Heberlein J. Dental diamond burs made with a new technology. J Prosthet Dent 1999;82:73-79.

3. Berggren U, Meynert G. Dental fear and avoidance: causes, symptoms and consequences. J Am Dent Assoc 1984;109:247-251.

4. Scott S, Hirschman R, Schroder K. Histological antecedents of dental anxiety. J Am Dent Assoc 1984;108:42-45.

5. Banerjee A, Kidd EA, Watson TF. In vitro evaluation of five alternative methods of carious dentine excavation. Caries Res 2000;34:144-150.

6. Rafique S, Fiske J, Banerjee A. Clinical trial an air-abrasion/chemomechanical operative procedure for the restor- ative treatment of dental patients. Caries Res 2003;37:360364.

7. Hugo B, Stassinakis A. Preparation and restoration of small interproximal carious lesions with sonic instruments. Pract Periodont Aesthet Dent 1998;10:353-359.

8. Trava-Airoldi VJ, Moro JR, Corat EJ, Goulart EC, Silva AP, Leite NF. Cylindrical CVD diamond as a high-performance small abrading device. Surf Coat Technol 1998;108:437-441.

9. Van Meerbeek B, De Munck J, Mattar D, Van Landuyt K, Lambrechts P. Microtensile Bond strengths of an etch\&rinse and self-etch adhesive to enamel and dentin as a function of surface treatment. Oper Dent 2003;28:647660.

10. Carvalho RCR, Freitas PM, Otsuki M, Eduardo CP, Tagami J. Influence of Er:YAG laser beam angle, work distance and energy density on dentin morphlogical changes: a SEM investigation. J Oral Laser Appl 2005;5:237-243.

11. Reis AF, Arrais CAG, Novaes PD, Carvalho RM, De Goes MF, Giannini M. Ultramorphological analysis of resin-dentin interfaces produced with water-based single-step and two-step adhesives: nanoleakage expression. J Biomed Mater Res B Appl Biomater 2004;71:90-98.

12. De Munck J, Van Landuyt K, Peumans M, Poitevin A, Lambrechts $P$, Braem M, Van Meerbeek B. A critical review of the durability of adhesion to tooth tissue: methods and results. J Dent Res 2005;84:118-132.

13. Perdigao J, Lambrechts P, van Meerbeek B, Tome AR, Vanherle G, Lopes AB. Morphological field emission-Sem study of the effect of six phosphoric acid etching agents on human dentin. Dent Mater 1996;12:262-271.

14. Tay FR, Carvalho RM, Sano H, Pashley DH. Effects of smear layer on the bonding of a self-etching primer to dentin. $J$ Adhes Dent 2000;2:99-116.

15. Ogata M, Harada N, Yamaguchi S, Nakajima M, Pereira PNR, Tagami J. Effects of differents burs on dentin bond strengths of self-etching primer bonding systems. Oper Dent 2001;26:375-382.

16. Van Meerbeek B, De Munck J, Yoshida Y, Inoue S, Vargas $M$, Vijay $P$, Van Landuyt $K$, Lambrechts $P$, Vanherle G. Buonocore memorial lecture. Adhesion to enamel and dentin: current status and future challenges. Oper Dent 2003;28:215-235.

17. Oliveira SS, Pugach MK, Hilton JF, Watanabe LG, Marshall SJ, Marshall GW. The influence of the dentin smear layer on adhesion: a self-etching primer vs. a total-etch system. Dent Mater 2003;19:758-767.

18. Tay FR, Pashley DH. Aggressiveness of contemporary selfetching systems. I: Depth of penetration beyond dentin smear layers. Dent Mater 2001;17:296-308.

19. Hibst R, Keller U. Experimental studies of the application 
of Er:YAG laser on dental hard substances: I. Measurement of the ablation rate. Lasers Surg Med 1989;9:338344.

20. Keller U, Hibst R. Experimental studies of the application of Er:YAG laser on dental hard substances: II. Light microscopic and SEM investigations. Lasers Surg Med 1989;9:344-351.

21. Visuri SR, Gilbert JL, Wright DD, Wigdor HA, Walsh JT. Shear Strength of composite bonded to Er:YAG laserprepared dentin. J Dent Res 1996;75:599-605.

22. Aoki A, Ishikawa I, Yamada T, Otsuki M, Watanabe $H$, Tagami J, Ando Y, Yamamoto H. Comparison between Er:YAG laser and convencional technique for root caries treatment in vitro. J Dent Res 1998;77:1404-1414.

23. De Munck J, Van Meerbeek B, Yudhira R, Lambrechts $P$, Vanherle G. Microtensile bond strength of two Erbium: YAG-lased vs. bur-cut enamel and dentin. Eur J Oral Sci 2002;110:322-329.

24. Trajtenberg CP, Pereira PNR, Powers JM. Resin bond strength and micromorphology of human teeth prepared with an erbium:YAG laser. Am J Dent 2004;17:331-336.

25. Ishizaka Y, Eguro T, Maeda T, Tanaka H. Effects of Er: YAG laser irradiation on human dentin: polarizing microscopic, light microscopic and microradiographic observations, and FT-IR analysis. Lasers Surg Med 2002;31:171176.

26. Camerlingo C, Lepore M, Gaeta GM, Riccio R, Riccio C, De Rosa A, De Rosa M. Er:YAG laser treatments on dentine surface: micro-Raman spectroscopy and SEM analysis. J Dent 2004;32:399-405.

27. Ceballos L, Toledano M, Osorio R, Tay FR, Marshall GW. Bonding to Er:YAG-laser treated dentin. J Dent Res 2002;81:119-122.

28. Donadio-Moura J, Gouw-Soares S, Freitas PM, Navarro RS, Powell LG, Eduardo CP. Tensile bond strength of a flowable composite resin to Er:YAG-laser-treated dentin. Lasers Surg Med 2005;36:351-355.

29. Los SA, Barkmeier WW. Effects of dentin air abrasion with aluminum oxide and hydroxyapatite on adhesive bond strength. Oper Dent 1994;19:169-175.

30. Banerjee A, Kidd EA, Watson TF. Scanning electron microscopic observations of human dentine after mechanical caries excavation. J Dent 2000;28:179-186.

31. Sazk H, Türrkmen C, Günday M. Effects of Nd:YAG laser, Air-abrasion and acid etching on human enamel and dentin. Oper Dent 2001;26:476-481.

32. Cehreli ZC, Yazici AR, Akca T, Özgünaltay G. A morphological and micro-tensile bond strength evaluation of a single-bottle adhesive to caries-affected human dentine after four different caries removal techniques. $J$ Dent
2003;31:429-435.

33. Watanabe I, Saimi Y, Nakabayashi N. Effect of smear layer on bonding to ground dentin-relationship between grinding condition and tensile bond strength. J Japanese Soc Dent Mater Devices 1994;13:101-108. 